\title{
Health professionals directly involved in the diagnosis, treatment, and care of patients with Covid-19
}

\section{Modesto Leite Rolim Neto'}

Productivity Scholarship at the Faculty of Medicine of Juazeiro do Norte - FMJ / ESTACIO, Juazeiro do Norte, Ceará, Brazil.

\section{$凶$}

Modesto Leite Rolim Neto Faculty of Medicine of Juazeiro do Norte - FMJ / ESTACIO, Juazeiro do Norte, Ceará, Brazil. modestorolim@yahoo.com.br

Edited by:

Juliana Ramos de Andrade

Keywords:

SARS-CoV-2

Mental Health

Psychiatric Repercussions

People on the front lines COVID-19.

\begin{abstract}
Introduction: Health professionals directly involved in the diagnosis, treatment, and care of patients with COVID-19 develop the insertion of psychic spaces for the installation of pain and psychological suffering and other mental health symptoms.

Objective: Carry out a analysis of the psychiatric repercussions based people on the front lines: Nurses, doctors, healthcare workers, and other medical professionals who are testing for and treating patients with COVID-19

Method: This current literature review has utilized literature reserves and scientific search engines MEDLINE, EMBASE and Web of Science. The search terms included, "SARS-CoV-2", "Mental Health," "psychiatric repercussions", "People on the front lines " "COVID-19". Specific choices of unique papers from each of the searches were identified. The inclusion criteria were relevance and availability of full-text. Papers were excluded on the basis of relevance and non-availability of full-text. Papers were identified in the general literature reserve as pertinent to the search terms.

Results: Work-related stress is a potential cause of concern for health professionals.

Conclusion: Evidence highlights some timely mental health care that needs to be developed urgently, such as: use of psychotropic drugs; specialized psychiatric treatments and appropriate mental; and health status updates for professionals in the Intensive Care Unit; psychological counseling; and psychotherapy techniques such as those based on the stress adaptation model.
\end{abstract}


The novel coronavirus (COVID-19) outbreak continues in cases and quarantines popping on the front lines? Nurses, doctors, healthcare workers, and other medical professionals who are testing for and treating patients with COVID-19 are at a higher risk of contracting it than the general public. What can they do to take care of themselves, physically and emotionally?' As if exposure to the COVID-19 during the global pandemic was not enough, healthcare workers face another risk: burnout due to overstress in an increasingly burdened healthcare system. The combination of stress and possible exposure puts healthcare professionals, from physicians and nurses to specialists, at greater risk of contracting COVID-19 and potentially spreading it to others. ${ }^{2}$

Given this critical situation, health professionals directly involved in the diagnosis, treatment, and care of patients with COVID-19 develop the insertion of psychic spaces for the installation of pain and psychological suffering and other mental health symptoms. The growing number of confirmed and suspected cases, overwhelming workload, depletion of personal protective equipment, extensive media coverage, lack of specific medications and inadequate support feelings can contribute to the mental burden of these health professionals. ${ }^{3-5}$

Work-related stress is a potential cause of concern for health professionals. It has been associated with anxiety including multiple clinical activities, depression in the face of the coexistence of countless deaths, long work shifts with the most diverse unknowns and demands in the treatment with patients with COVID-19. Therefore, it is an important indicator of psychic exhaustion. 6,7

The difficulty in assessing the extent to which health professionals have been affected emotionally is difficult because the Centers for Disease Control and Prevention (CDC), medical associations or unions of health professionals have not released worldwide data yet. ${ }^{8}$ Dozens of health care professionals on the front lines of the coronavirus pandemic have become ill with the coronavirus and more have been in quarantine after being exposed to it. ${ }^{9}$

Evidence highlights some timely mental health care that needs to be developed urgently, such as: use of psychotropic drugs; specialized psychiatric treatments and appropriate mental; and health status updates for professionals in the Intensive Care Unit; regular updates to address their sense of uncertainty and fear; psychological counseling ; provision of emotional and behavioral responses to extraordinary stress, and psychotherapy techniques such as those based on the stress adaptation model. ${ }^{10-12}$

Modesto Leite Rolim Neto

https://orcid.org/0000-0001-9379-2120

\section{Acknowledgements}

The authors would like to thank the Research Group: Suicidology - Universidade Federal do Ceará (UFC) and Brazilian National Council for Scientific and Technological Development (CNPq) - institution linked to the Brazilian Department of Science, Technology and Scientific Writing Lab, Medicine School Universidade Federal of Cariri (UFCA).

\section{Funding}

The Research Group: Suicidology - Universidade Federal do Ceará (UFC) and Brazilian National Council for Scientific and Technological Development (CNPq) - institution linked to the Brazilian Department of Science, Technology and Innovation to encourage research in Brazil.

\section{Conflict of interests}

The authors declare that they have no competing interests.

\section{Ethical Statement}

We declare that there is no ethical conflict.

All authors agree to send the manuscript for publication.

\section{References}

1. Choudhary V. Addressing anxiety about the coronavirus (COVID-19): Healthcare workers [Internet]. Magellan Health Insights: Magellan Health Insights; 2020 [cited 2021]. Available from: https://magellanhealthinsights. com/2020/03/12/addressing-anxiety-aboutthe-coronavirus-covid-19-healthcare-workers/.

2. Lagasse J. Healthcare workers risk burnout, exposure in wake of coronavirus pandemic [Internet]. Health Care Finance: Health Care Finance; 2020 [cited 2021]. Available from: https://www.healthcarefinancenews.com/news/ healthcare-workers-risk-burnout-exposure-wakecoronavirus-pandemic.

3. Luyan S. A notification to set up nationwide psychological assistance hotlines against the 2019-nCoV outbreak [Internet]. The State Council of China: The State Council of China; 2020 [cited 2021]. Available from: http://www.gov.cn/ xinwen/2020-02/02/content_5473937.htm. 
4. Lai J, Ma S, Wang Y, Cai Z, Hu J, Wei N, . . Hu S. Factors Associated With Mental Health Outcomes Among Health Care Workers Exposed to Coronavirus Disease 2019. JAMA Netw Open 2020;3(3):e203976 Doi:10.1001/ jamanetworkopen.2020.3976

5. Lee AM, Wong JG, McAlonan GM, Cheung V, Cheung C, Sham PC, . . Chua SE. Stress and psychological distress among SARS survivors 1 year after the outbreak. Can J Psychiatry 2007;52(4):233-240 Doi: $10.1177 / 070674370705200405$

6. Adams JG and Walls RM. Supporting the Health Care Workforce During the COVID-19 Global Epidemic. JAMA 2020;323(15):1439-1440 Doi:10.1001/jama.2020.3972

7. Kushal A, Kumar S, Mehta $M$ and Singh $M$. Study of Stress among Health Care Professionals: A Systemic Review. International Journal of Research Foundation of Hospital and Health Care Administration 2018;6(1):6-11 Doi:10.5005/ipjournals-10035-1084

8. Bernstein L, Boburg S, Sacchetti M and Brown E. Covid-19 hits doctors, nurses and EMTs, threatening health system [Internet]. The Washington Post: The Washington Post; 2020 [cited 2021]. Availablefrom: https://www.washingtonpost.com/health/covid19-hits-doctors-nurses-emts-threatening-healthsystem/2020/03/17/f21 147e8-67aa- 11 eab313-df458622c2cc_story.html.

9. Guzman J. US health care workers furloughed, quarantined due to coronavirus exposure [Internet]. The Hill: The Hill; 2020 [cited 2021]. Available from: https://thehill.com/changingamerica/well-being/prevention-cures/488059-ushealth-care-workers-furloughed-quarantined.

10. Xiang YT, Yang Y, Li W, Zhang L, Zhang Q, Cheung $\mathrm{T}$ and $\mathrm{Ng} \mathrm{CH}$. Timely mental health care for the 2019 novel coronavirus outbreak is urgently needed. Lancet Psychiatry 2020;7(3):228-229 Doi:10.1016/s2215-0366(20)30046-8

11. Maunder R, Hunter J, Vincent L, Bennett J, Peladeau N, Leszcz M, . . Mazzulli T. The immediate psychological and occupational impact of the 2003 SARS outbreak in a teaching hospital. Cmai 2003;168(10):1245-1251

12. Folkman S and Greer S. Promoting psychological well-being in the face of serious illness: when theory, research and practice inform each other. Psychooncology 2000;9(1):1 1-19 Doi:10.1002/ (sici) 1099-1611(200001/02)9:1<1 1::aidpon424>3.0.co; $2-z$ 